OPEN ACCESS

Edited by:

Jakub Fichna,

Medical University of Lodz, Poland

Reviewed by:

David Bulmer,

Barts and The London School

of Medicine and Dentistry,

United Kingdom

Mohammad Bashashati,

Texas Tech University Health

Sciences Center, United States

*Correspondence.

Maria Cecilia Giron

cecilia.giron@unipd.it

†These authors have contributed equally to this work

Specialty section: This article was submitted to Gastrointestinal and Hepatic

Pharmacology,

a section of the journal

Frontiers in Pharmacology

Received: 18 February 2017

Accepted: 22 May 2017

Published: 08 June 2017

Citation:

Caputi V, Marsilio I, Cerantola S,

Roozfarakh M, Lante I, Galuppini F,

Rugge M, Napoli E, Giulivi C, Orso G

and Giron MC (2017) Toll-Like

Receptor 4 Modulates Small Intestine

Neuromuscular Function through

Nitrergic and Purinergic Pathways.

Front. Pharmacol. 8:350.

doi: 10.3389/fphar.2017.00350

\section{Toll-Like Receptor 4 Modulates Small Intestine Neuromuscular Function through Nitrergic and Purinergic Pathways}

\author{
Valentina Caputit', Ilaria Marsilio ${ }^{1 \dagger}$, Silvia Cerantola, ${ }^{1,2}$, Mona Roozfarakh ${ }^{3}$, \\ Isabella Lante ${ }^{2}$, Francesca Galuppini ${ }^{4}$, Massimo Rugge ${ }^{4}$, Eleonora Napoli ${ }^{5}$, \\ Cecilia Giulivi5,6, Genny Orso ${ }^{7}$ and Maria Cecilia Giron ${ }^{1 *}$
}

\begin{abstract}
'Department of Pharmaceutical and Pharmacological Sciences, School of Medicine, University of Padova, Padova, Italy, ${ }^{2}$ San Camillo Hospital, Treviso, Italy, ${ }^{3}$ Medway School of Pharmacy, Universities of Kent and Greenwich at Medway, Kent, United Kingdom, ${ }^{4}$ Department of Medicine, University of Padova, Padova, Italy, ${ }^{5}$ Department of Molecular Biosciences, School of Veterinary Medicine, University of California, Davis, Davis, CA, United States, ${ }^{6}$ Medical Investigation of Neurodevelopmental Disorders Institute (M.I.N.D.), University of California, Davis, Sacramento, CA, United States, ${ }^{7}$ IRCCS "E. Medea" Bosisio Parini, Lecco, Italy
\end{abstract}

Objective: Toll-like receptors (TLRs) play a pivotal role in the homeostatic microflorahost crosstalk. TLR4-mediated modulation of both motility and enteric neuronal survival has been reported mainly for colon with limited information on the role of TLR4 in tuning structural and functional integrity of enteric nervous system (ENS) and in controlling small bowel motility.

Methods: Male TLR4 knockout (TLR4-/-, $9 \pm 1$ weeks old) and sex- and agematched wild-type (WT) C57BL/6J mice were used for the experiments. Alterations in ENS morphology and neurochemical code were assessed by immunohistochemistry whereas neuromuscular function was evaluated by isometric mechanical activity of ileal preparations following receptor and non-receptor-mediated stimuli and by gastrointestinal transit.

Results: The absence of TLR4 induced gliosis and reduced the total number of neurons, mainly nNOS ${ }^{+}$neurons, in ileal myenteric plexus. Furthermore, a lower cholinergic excitatory response with an increased inhibitory neurotransmission was found together with a delayed gastrointestinal transit. These changes were dependent on increased ileal non-adrenergic non-cholinergic (NANC) relaxations mediated by a complex neuronal-glia signaling constituted by $\mathrm{P} 2 \mathrm{X} 7$ and $\mathrm{P} 2 \mathrm{Y} 1$ receptors, and NO produced by nNOS and iNOS.

Conclusion: We provide novel evidence that TLR4 signaling is involved in the finetuning of P2 receptors controlling ileal contractility, ENS cell distribution, and inhibitory NANC neurotransmission via the combined action of $\mathrm{NO}$ and adenosine-5'-triphosphate (ATP). For the first time, this study implicates TLR4 at regulating the crosstalk between glia and neurons in small intestine and helps to define its role in gastrointestinal motor abnormalities during dysbiosis.

Keywords: toll-like receptor 4, enteric nervous system, small bowel, intestinal motility, intestinal transit, innate immunity, gut microbiota, knockout mice 


\section{INTRODUCTION}

The functional link between endogenous gut microbes and their host regulates the balance between commensalism and parasitism on the microbial side, and between infection and resistance on the host side. Although this complex bidirectional communication is still not fully understood, it may be involved in the onset of gastrointestinal functional disorders (GFD), such as irritable bowel syndrome (IBS) (Barbara et al., 2016).

Commensal enteric microbiota efficiently influences innate defenses by preventing pathogenic bacteria from crossing the mucosal barrier (Kamada et al., 2013). However, this delicate balance can be perturbed by several factors (e.g., stress, drugs, and inflammation) leading to GFD as a result of a vicious cycle in which host dysfunctions affect microflora environment leading to dysbiosis and vice versa (Rakoff-Nahoum et al., 2004; Lee and Lee, 2014). These disorders are characterized by intestinal barrier breakdown, bacterial translocation and changes in motility (Bischoff et al., 2014), and appear to be driven by abnormal responses to microbiota-derived molecules via stimulation of Toll-like receptors (TLRs) (Rakoff-Nahoum et al., 2004; Barbara et al., 2016).

The finding of TLRs expressed in both central and enteric nervous systems (CNS and ENS) (Barajon et al., 2009; Okun et al., 2011), acting as key sensors not only for damage-associated molecular patterns but also for physiological factors, strongly extends the impact of TLRs in the nervous system beyond their role in controlling host immune responses (Okun et al., 2011). In other words, in absence of any underlying immune response, the location in the nervous system of TLRs and their activation by endogenous ligands underlies their role as key players in regulating neurodevelopment and neuroplasticity (Aravalli et al., 2007; Okun et al., 2011). Among all TLRs, TLR4 is the best characterized pathogen-recognition receptor and recently recognized to modulate ENS phenotype and function (Anitha et al., 2012). We recently showed the expression of TLR4 mRNA transcripts in freshly isolated smooth muscle cells and enteric glial cells (EGCs) but not in resident macrophages and dendritic cells (Brun et al., 2015). In vivo, under steadystate conditions, TLR4 is generally absent or detected in very small amounts in intestinal epithelial cells and in immune cells located in the subepithelial lamina propria, in order to avoid inappropriate activation despite the omnipresent microbiota (Cario, 2010).

Several studies advocate for a role of TLRs in ENS homeostasis (Kabouridis and Pachnis, 2015). TLR2 $2^{-/-}$mice show disrupted ENS structural and functional integrity, similar to that observed in antibiotic-induced microbiota depleted wild-type mice (Brun et al., 2013). Germ-free, antibiotic-treated mice and TLR4 signaling-defective (Tlr4 $\left.4^{\text {Lps-d}}\right)$ mice show similar colonic dysmotility and fewer $\mathrm{nNOS}^{+}$neurons (Anitha et al., 2012). Furthermore, treatment with low lipopolysaccharide (LPS) levels promotes the survival of cultured enteric neurons in an NF- $\mathrm{\kappa B}-$ dependent mechanism (Anitha et al., 2012).

Based on these evidences, we sought to characterize the role of TLR4 in tuning structural and functional integrity of
ENS and in controlling small bowel contractility for identifying the signaling pathways involved in neuroimmune cross talk, hopefully translatable into novel therapeutic strategies for patients with GFD.

\section{MATERIALS AND METHODS}

\section{Animals}

Male TLR4 $^{-/-}$(B6.B10ScN-Tlr $4^{\text {lps-del }} /$ JthJ; $9 \pm 1$ weeks old) and sex- and age-matched wild-type (WT) C57BL/6J mice (Jackson Laboratories, Bar Harbor, ME, United States) were housed in individually ventilated cages (IVC) at the animal facility of the Department of Pharmaceutical and Pharmacological Sciences, University of Padova. To normalize gut microbiota, mice colonies from both groups were housed in the same room and generally in the same cages, and maintained by the same personnel. All animals were specific pathogenfree and given standard chow diet and tap water ad libitum. All experimental protocols were approved by the Animal Care and Use Ethics Committee, University of Padova and Italian Ministry of Health (authorization number: 1142/2015-PR) and are reported in compliance with ARRIVE guidelines (McGrath and Lilley, 2015).

\section{Histology}

Ileal specimens, fixed in $10 \%$ buffered formalin, embedded in paraffin and cut into $4 \mu \mathrm{m}$-sections were stained with haematoxylin and eosin (H\&E) (Dall'Olmo et al., 2014). Ten slides for each genotype were analyzed blindly.

\section{Intestinal Paracellular Permeability}

Intestinal paracellular permeability was assessed as previously described (Aubé et al., 2006). Briefly, WT and TLR4 ${ }^{-/-}$mice were gavaged orally with absorbable fluorescein isothiocyanate (FITC)-dextran ( $4 \mathrm{kDa}$ molecular weight; $200 \mu \mathrm{l}, 600 \mathrm{mg} / \mathrm{kg}$ body weight). Preliminary experiments at various time points $(0,0.5,1,2,4$, and $6 \mathrm{~h})$ showed that the appearance in blood of low molecular weight FITC-dextran peaked at $4 \mathrm{~h}$ following oral administration in WT and TLR4 ${ }^{-/-}$ mice. After $4 \mathrm{~h}$, FITC-dextran serum concentration was determined using a fluorimeter (PerkinElmer, Milan, Italy) at $490 / 530 \mathrm{~nm}$.

\section{Gastrointestinal Transit}

WT and TLR4 ${ }^{-1-}$ mice were gavaged orally with $70-\mathrm{kDa}$ FITC-dextran $(25 \mathrm{mg} / \mathrm{ml}$ in $0.9 \%$ saline solution). Preliminary experiments at various time points $(0,30,45,60,75$, and $90 \mathrm{~min}$ ) showed that the distribution of high molecular weight FITC-dextran peaked at $30 \mathrm{~min}$ in the ileum following oral administration in WT and TLR4 ${ }^{-/-}$mice. After $30 \mathrm{~min}$, the stomach and caecum were examined separately while small intestine and colon were divided into 10 and 3 comparable length-segments, respectively. Gastrointestinal transit was determined using the intestinal geometric center of FITCdextran distribution throughout the intestine as described previously (Aubé et al., 2006; Brun et al., 2013). Gastric emptying 
was determined by percentage of fluorescent probe that emptied the stomach (Aubé et al., 2006).

\section{Pellet Frequency and Fecal Water Content}

Fecal pellet output was assessed daily as previously described. Mice were observed for $60 \mathrm{~min}$. Fecal pellet numbers, fecal wet weights and dry weights were determined. The difference between wet and dry weights was used to calculate fecal water content (McQuade et al., 2016).

\section{In Vitro Contractility Studies}

Contractility studies were performed as previously described (Giron et al., 2008; Brun et al., 2013; Zoppellaro et al., 2013). Briefly, $1-\mathrm{cm}$ longitudinal segments from the distal ileum were mounted in 10-mL-organ baths equilibrated for $30 \mathrm{~min}$ in Krebs solution $\left(37^{\circ} \mathrm{C}\right)$. Changes in muscle tension were recorded by isometric transducers connected to a PowerLab4/30 system (ADInstruments, Oxford, United Kingdom). Carbachol (0.001-100 $\mu \mathrm{M})$ and ADP $(0.001-1 \mathrm{mM})$ dose-response curves were obtained cumulatively. Non-receptor-mediated contractile responses to $60 \mathrm{mM} \mathrm{KCl}$ were assessed. Neuronal-mediated contractions were analyzed following electrical field stimulation (EFS; $0-40 \mathrm{~Hz} ; 40 \mathrm{~V}$ ) in basal conditions or in non-adrenergic non-cholinergic (NANC) conditions, obtained by adding $1 \mu \mathrm{M}$ guanethidine and $1 \mu \mathrm{M}$ atropine to the organ bath. $10 \mathrm{~Hz}$ EFS-mediated NANC responses were evaluated in presence of the pan-NOS inhibitor L-NAME $(100 \mu \mathrm{M})$, the iNOS inhibitor $1400 \mathrm{~W}(10 \mu \mathrm{M})$, the P1-purinoceptor antagonist theophylline $(100 \mu \mathrm{M})$, the P2-purinoceptor antagonist suramin $(100 \mu \mathrm{M})$, the P2Y1 receptor (P2Y1R) antagonist MRS2500 $(1 \mu \mathrm{M})$ or the P2X7R antagonist A804598 (0.1 $\mu \mathrm{M})$.

Ten hertz-EFS-mediated tachykininergic responses were recorded in NANC conditions with $100 \mu \mathrm{M}$ L-NAME. Contractile responses were expressed as gram tension/gram dry tissue weight of ileal segments. Ileal relaxation was calculated as the percentage reversal of the initial gram tension/dry tissue weight, setting $100 \%$ inhibition as the maximum relaxation (Zizzo et al., 2003).

\section{Acetylcholine Esterase and NADPH-Diaphorase Biochemical Staining}

Distal ileal $10 \mathrm{~cm}$-segments were filled with fixative solution (4\% paraformaldehyde in PBS) for $1 \mathrm{~h}$ at room temperature. Using a dissecting microscope, whole mount specimens of longitudinal muscle-myenteric plexus (LMMP) were prepared as previously described (De Mello et al., 2009; Brun et al., 2013). Briefly, LMMP preparations were gently stretched and pinned down on a wax support and subjected to acetylcholine esterase (AChE) or NADPH-diaphorase (NADPHd) biochemical staining (Anitha et al., 2006). Stained tissues mounted on glass slides were observed using a Leica DMI4000 B microscope (Leica Microsystems $\mathrm{GmbH}$, Wetzlar, Germany). $\mathrm{AChE}^{+}$myenteric fibers and $\mathrm{NADPHd}^{+}$neuronal cells analysis was performed blindly by counting fibers or neurons in 10 randomly-chosen images per mouse (six animals/group), as previously described (De Mello et al., 2009).

\section{Immunohistochemistry}

Longitudinal muscle-myenteric plexus whole mount preparations were gently stretched and pinned down on a wax support and permeabilized in PBT (PBS with $0.3 \%$ Triton $\mathrm{X}-100$ ) and blocked with $2 \%$ bovine serum albumin (BSA) for $1 \mathrm{~h}$ at room temperature, as previously reported (Brun et al., 2013). Distal ileum (0.5 cm-segments) were frozen in optimal cutting temperature mounting medium (OCT), sectioned ( $7 \mu \mathrm{m}$-thick) with a cryostat (Leica CM $1850 \mathrm{UV}$, Milan, Italy) and then mounted onto Superfrost Plus slides. From each ileal specimen, 100 sequential $7 \mu \mathrm{m}$-cross-sections were cut on a cryostat and 6-8 sections were subjected to immunohistochemistry as previously described (Giron et al., 2008; Zoppellaro et al., 2013). LMMP whole mount preparations or ileal cryosections were then incubated overnight at room temperature with the following antibodies: chicken polyclonal anti-mouse glial fibrillary acidic protein (GFAP; 1:100; Abcam, Milan, Italy), rabbit polyclonal anti-human GFAP (1:200; Merck Millipore Corporation, Milan, Italy), mouse biotin-conjugated anti-human HuC/D (1:50; Thermo Fisher Scientific, Milan, Italy), rabbit polyclonal anti-mouse neuronal nitric oxide synthase (nNOS, 1:100; Thermo Fisher Scientific, Milan, Italy), rabbit polyclonal anti-human inducible NOS (iNOS; 1:50, Santa Cruz Biotechnology, Milan, Italy), rabbit polyclonal anti-human vasoactive intestinal peptide (VIP, 1:100; GenWay Biotech, Milan, Italy), rabbit polyclonal anti-human P2X7 receptor-ATTO-488 (1:100; Alomone labs, Jerusalem, Israel), rabbit polyclonal anti-human $\mathrm{P} 2 \mathrm{Y} 1$ receptor (1:100; Alomone labs, Jerusalem, Israel), rabbit monoclonal anti-human $S 100 \beta$ (1:100; Merck Millipore Corporation, Milan, Italy) and guinea pig polyclonal anti-mouse substance P (1:100; Abcam, Milan, Italy). Then cryosections or LMMP whole mount preparations were washed and incubated for $2 \mathrm{~h}$ at room temperature with the following secondary antibodies: Alexa Fluor 488-conjugated goat anti-chicken IgG (1:1000; Thermo Fisher Scientific, Milan, Italy), Alexa Fluor 488-conjugated goat anti-guinea pig IgG (1:500; Thermo Fisher Scientific, Milan, Italy), Alexa Fluor 488-conjugated goat anti-rabbit IgG (1:1000; Thermo Fisher Scientific, Milan, Italy), DyLight 649-conjugated goat anti-rabbit IgG (1:500, Jackson ImmunoResearch Laboratories, Milan, Italy) or Alexa Fluor 555-conjugated streptavidin (1:1000, Thermo Fisher Scientific, Milan, Italy). Nuclei were stained with TOTO-3 (1:500; Thermo Fisher Scientific, Milan, Italy) or with 4',6-diamidino-2-phenylindole, dihydrochloride (DAPI) (1:1000; Thermo Fisher Scientific, Milan, Italy) added together with the secondary antibodies. After three washes, LMMP whole mount preparations or cryosections were mounted on glass slides using a Mowiol Mounting Medium (100-mM Tris- $\mathrm{HCl}$ ( $\mathrm{pH}$ 8.5), 9\% Mowiol 4-88, 25\% glycerol and 0.1\% DABCO). Negative controls were obtained by incubating sections with isotype-matched control antibodies at the same concentration as primary antibody and/or pre-incubating each antibody with the corresponding control peptide (final concentration as indicated by manufacturer's instructions) (Brun et al., 2013). 


\section{Confocal Image Acquisition and Analysis}

Images were acquired using a Nikon D-Eclipse C1 confocal microscope (Nikon Instruments, Florence, Italy), equipped with an oil-immersion Nikon Plan-Apo $60 \times / 1$.4 objective or a lowmagnification Nikon Plan Fluor $20 \times / 0.5$ objective. Five Z-series images (10 planes for ileum cryosections or 15 planes for LMMP whole mount preparations) of 1024 pixels $\times 1024$ pixels were processed as maximum intensity projections. All microscope settings were kept constant for all images. Fluorescence intensity of S100 $\beta$, substance P, P2X7 receptors, P2Y1 receptors and iNOS was assessed for each antigen in 20 images per mouse ( $N=5$ mice/group), as previously reported (Arqués et al., 2014). The obtained fluorescence values indicating the fluorescence intensity of each protein of interest (i.e., S100 $\beta$, substance P, $\mathrm{P} 2 \mathrm{X} 7$ receptors, $\mathrm{P} 2 \mathrm{Y} 1$ receptors or iNOS) were normalized for the fluorescence intensity of its own TOTO-3 or DAPI and were reported as mean \pm SEM, as previously described (Orso et al., 2005).

Fluorescence intensity of $\mathrm{GFAP}^{+}$fibers was determined by applying the skeleton analysis method developed to quantify brain microglia morphology as previously described (Morrison et al., 2013). Briefly, for skeleton analysis, the maximum intensity projection of the $\mathrm{GFAP}^{+}$channel was enhanced to image all enteric glial processes, followed by noise de-speckling to eliminate single-pixel background fluorescence. After converting the resulting images to binary, they were skeletonized using ImageJ software and then analyzed by the AnalyzeSkeleton plugin to determine the number of endpoints per frame and process length. These data were normalized to a total area of $13.14 \mathrm{~mm}^{2}$, obtained from 20 images per mouse $(N=5$ mice/group $)$ in order to assess changes in EGCs. Analyses of images and related fluorescence intensity were performed using ImageJ software (Fiji, version 1.51n).

In ileal LMMP whole mount preparations, total neuron population analysis was performed by counting $\mathrm{HuC} / \mathrm{D}^{+}$cells in 10 randomly-chosen images per mouse ( $N=8$ mice/group). The total number of $\mathrm{HuC} / \mathrm{D}^{+}$neurons was recorded in each image and normalized to the total area of $4.05 \mathrm{~mm}^{2}$. To evaluate the distribution of nitrergic and VIPergic neurons in ileal myenteric plexus, the number of nNOS ${ }^{+}$and $\mathrm{VIP}^{+}$enteric neurons was blindly counted in 10 randomly-chosen images per mouse $(N=8$ mice/group) and normalized to the total area of $4.05 \mathrm{~mm}^{2}$.

\section{Chemicals}

Unless otherwise specified, all chemicals were obtained from Sigma-Aldrich (Milan, Italy) and were of the highest commercially available analytical grade. OCT was purchased from Kaltek (Padua, Italy), PFA was from Electron Microscopy Sciences-Società Italiana Chimici (Rome, Italy), $\beta$-NADPH was obtained from Diagnostic Brokers Associated (Milan, Italy), and Triton-X-100 was from Applichem (Milan, Italy).

\section{Statistical Analysis}

All data are expressed as mean \pm SEM. Differences between the experimental groups were assessed using paired or unpaired Student's $t$-test and one-way or two-way analysis of variance
(ANOVA), followed by post hoc Bonferroni test. Data were analyzed using GraphPad Prism 3.03 (San Diego, CA, United States). The results were considered statistically significant at $p<0.05$; " $N$ " values indicate the number of animals.

\section{RESULTS}

\section{TLR4 Influences Ileal Morphology and ENS Architecture}

Since TLR4 expression is required for normal growth (including villus height) of the small intestine (Riehl et al., 2015), we sought to determine whether the absence of TLR4 influences structural architecture by examining hematoxylin and eosinstained sections. In agreement with previous findings (Riehl et al., 2015), TLR4 ${ }^{-1-}$ ileal morphology was comparable to WT, except for villi height, which was significantly diminished $(349 \pm 9 \mu \mathrm{m}$ in WT mice vs. $306 \pm 15 \mu \mathrm{m}$ in $\mathrm{TLR}^{-/-}$mice; $N=20$ animals/group). No significant differences in serum levels of absorbable FITC-dextran were found between TLR $4^{-/-}$and WT mice $(0.42 \pm 0.1 \mu \mathrm{g} / \mathrm{ml}$ and $0.32 \pm 0.1 \mu \mathrm{g} / \mathrm{ml}$, respectively; $N=12$ animals/group), to indicate no alterations in intestinal permeability. Considering that TLR4 is expressed in ENS (Rumio et al., 2006; Barajon et al., 2009), the impact of TLR4 absence on ENS integrity was evaluated by immunohistochemistry. In ileal cryosections, a 1.84-fold increase in the immunoreactivity of the glial marker S100 $\beta$ was found in TLR4 ${ }^{-/-}$myenteric plexus (Figures 1A,B). These increases in $S 100 \beta$ immunoreactivity were associated to a 3.1-fold increase in process length of $\mathrm{GFAP}^{+}$ gliofilaments in TLR4 ${ }^{-/-}$ENS (Figures 1C-E).

\section{Absence of TLR4 Impairs Gastrointestinal Motility}

Previous studies have shown a reduced gastrointestinal transit $4 \mathrm{~h}$ after non-absorbable FITC-dextran administration in $\mathrm{C} 3 \mathrm{H} / \mathrm{HeJ}$ mice with a spontaneous point mutation in Tlr4 gene (Tlr $4^{L p s-d}$ ) (Anitha et al., 2012). We hypothesized that the same functional impairment could be present in TLR4 ${ }^{-/}$mice (B6.B10ScNTlr $\left.4^{1 \mathrm{ps}-\mathrm{del}}\right)$, which are homozygous for a null mutation of Tlr4 gene.

In WT mice, the non-absorbable FITC-dextran transited through the gastrointestinal tract over a 30-min period and localized at the terminal ileum (Figure 2A). Conversely, a significant reduction of geometric center and gastric emptying was observed in TLR4 ${ }^{-/-}$mice (Figures 2B,C). The number of fecal pellets/hour and stool water content were significantly lower in TLR4 ${ }^{-/-}$mice compared to WT mice (Figures 2D,E).

\section{TLR4 Deficiency Affects Excitatory Neurotransmission}

Based on the delayed gastrointestinal transit, we assessed spontaneous contractility that resulted comparable in frequency and amplitude in both genotypes (Figures $\mathbf{3 A}, \mathbf{B}$ ). To evaluate excitatory responses, cumulative concentration-response curves to the non-selective cholinergic receptor agonist, carbachol (CCh) were performed. Ileal segments from $\mathrm{TLR}^{-/-}$mice 


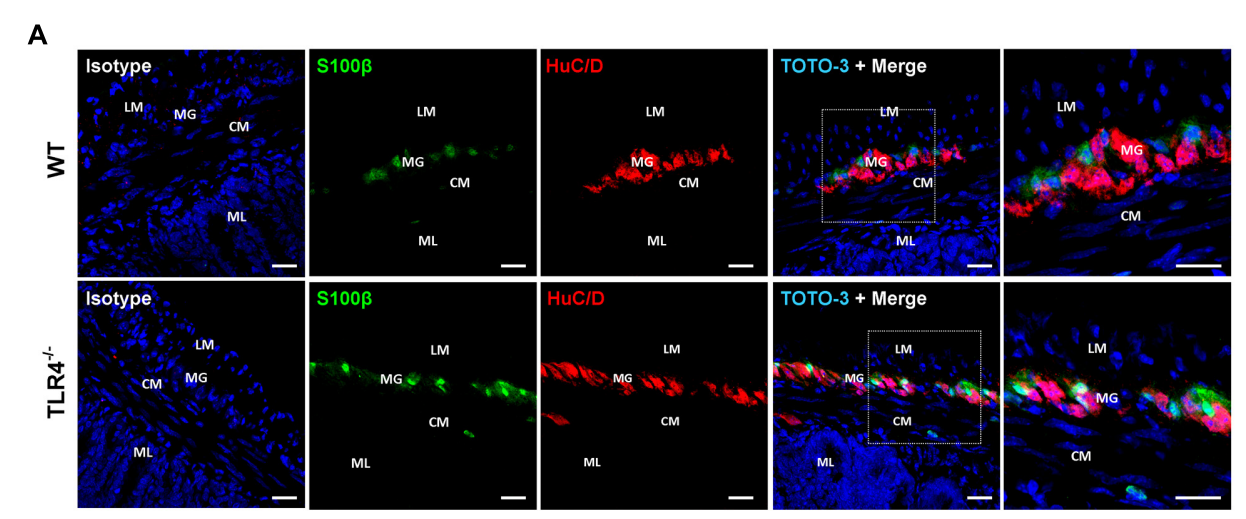

B

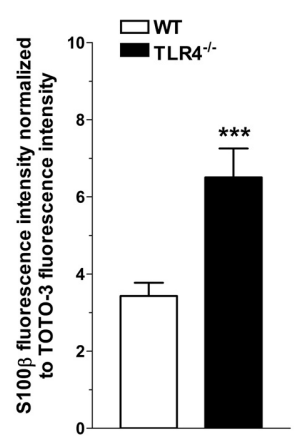

D

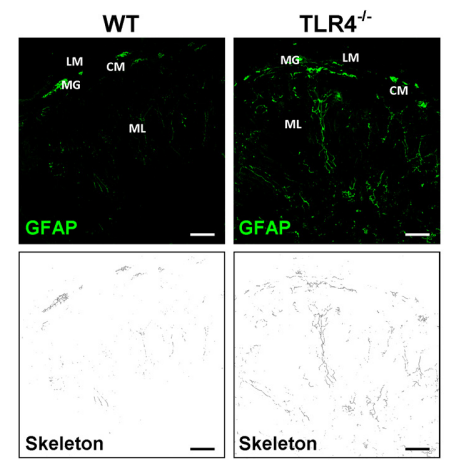

C

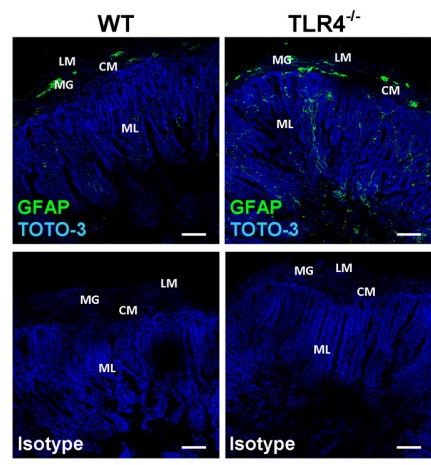

E

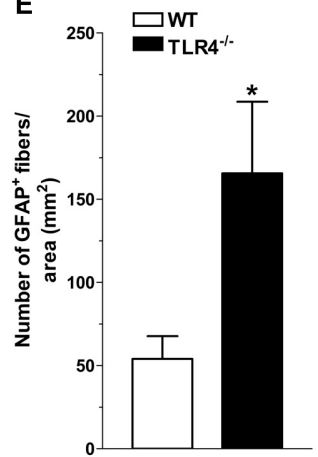

FIGURE 1 | TLR4 deficiency alters glial phenotype. Representative confocal microphotographs (A) of HuC/D (red) and S100 $\beta$ (green) distribution in wild-type (WT) and TLR4 ${ }^{-/}$- cryosections and quantification (B) of $S 100 \beta$ fluorescence intensity (bars $=22 \mu \mathrm{m}$ ). (C) Representative confocal microphotographs of glial fibrillary acidic protein (GFAP) distribution in WT and TLR4 ${ }^{-/-}$cryosections (bars $=75 \mu \mathrm{m}$ ). (D) Representative confocal maximum intensity projection of GFAP ${ }^{+}$channel with the corresponding skeleton images. (E) Number of GFAP ${ }^{+}$glial processes. Cell nuclei were stained with TOTO-3 (blue). ${ }^{*} P<0.05,{ }^{* * *} P<0.001$ vs. WT ( $N=5$ mice/group). LM, longitudinal muscle; CM, circular muscle; MG, myenteric ganglia; ML, mucosal layer.

showed a significant downward shift of the concentrationresponse curve to $\mathrm{CCh}$ and a significant related decrease in the maximum response compared to $\mathrm{WT}\left(E_{\max }=-25.6 \pm 7.5 \%\right.$; Figure 3C). However, the response to high potassium-induced depolarization was similar in both genotypes (Figure 3D).

Since ENS structural abnormalities have been described in Tlr $4^{\text {Lps-d }}$ mice (Anitha et al., 2012), we sought to test neuromuscular function by analyzing frequency-response curves to EFS. Altered neurotransmission in TLR4 ${ }^{-/-}$ileal segments was reflected by reduced EFS-elicited contractions (by
$28.5 \pm 9.7 \%$ at $10 \mathrm{~Hz}$, Figure $4 \mathrm{~A})$. The EFS-induced contractions up to $10 \mathrm{~Hz}$ were of neuronal cholinergic origin as confirmed by their sensitivity to tetrodotoxin (TTX) and to the muscarinic receptor blocker atropine, as previously shown (Brun et al., 2013). However, no changes in the number of $\mathrm{AChE}^{+}$fibers were found in TLR $4^{-/}$whole-mount preparations (Figures $4 \mathrm{~B}, \mathrm{C}$ ).

To evaluate the contribution of other excitatory neurotransmitters besides acetylcholine, we evaluated the post-stimulus excitatory responses in NANC conditions, which are determined by tachykininergic neurotransmission (Lecci, 

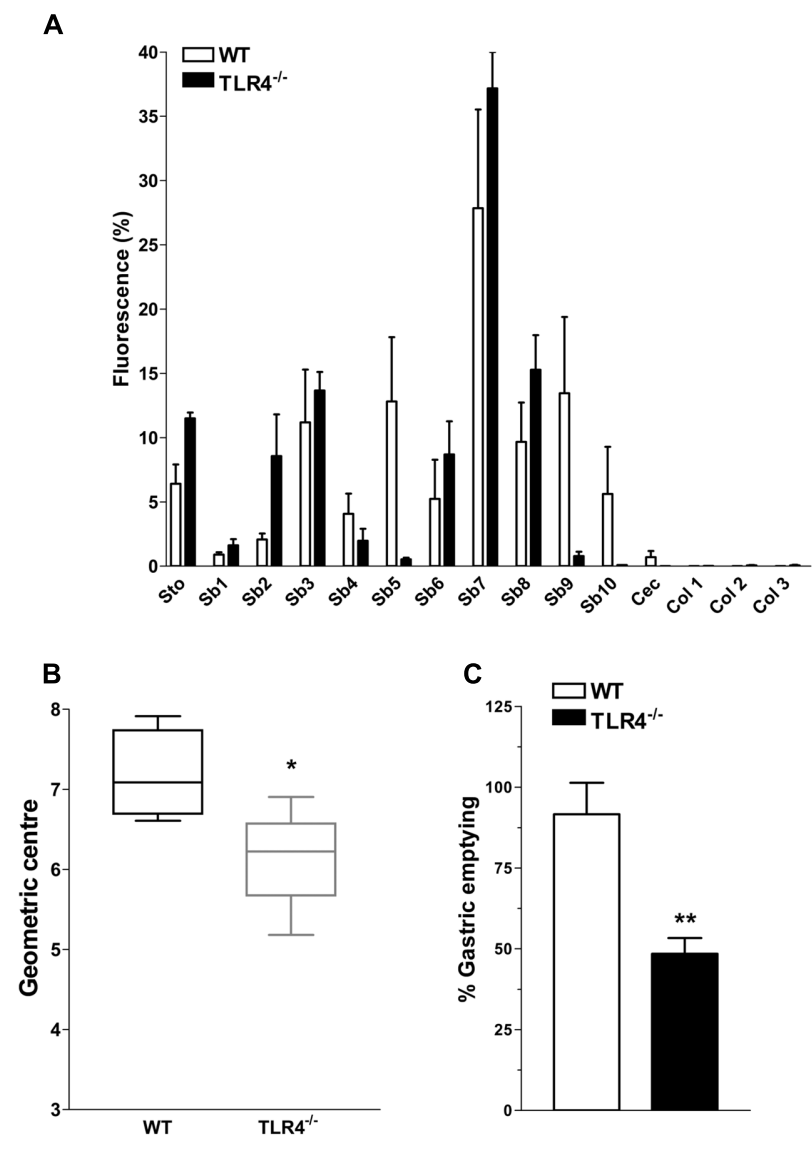

D
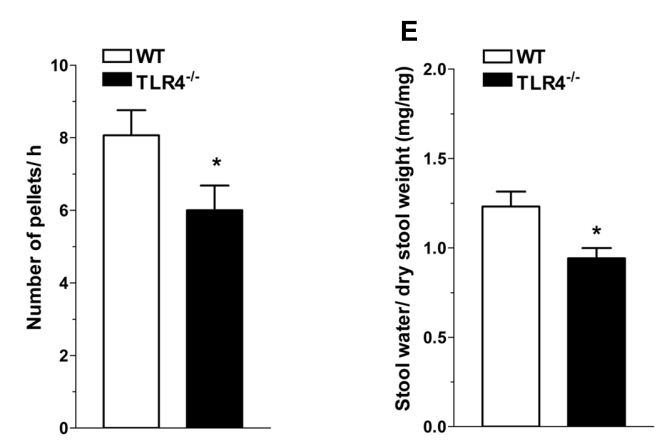

FIGURE 2 | TLR4 signaling influences gastrointestinal transit and gastric emptying. (A) Percentage of non-absorbable fluorescein isothiocyanate (FITC)-dextran distribution along the gastrointestinal tract (stomach, Sto; small bowel, Sb 1-10; caecum, Cec; and colon, Col 1-3), (B) geometric center, (C) percentage of gastric emptying, (D) pellet frequency per hour, (E) fecal water content in WT and TLR4 ${ }^{-/-}$mice. ${ }^{*} P<0.05,{ }^{* *} P<0.01$ vs. WT $(N=12$ mice/group).

2002). In WT mice, NANC responses evoked by EFS determined a transient relaxation of ileal preparations, followed by TTXsensitive excitatory responses (Figures 5A,B) (Zizzo et al., 2003). These excitatory responses were significantly reduced in TLR4 ${ }^{-/}$ileal segments (by $30 \pm 8.3 \%$; Figures 5A,B). Upon addition of L-NAME, a tachykinin-mediated excitatory response (Lecci, 2002) was found in TLR4 ${ }^{-/-}$preparations comparable to
WT (Figure 5C). Accordingly, no differences were observed in the immunofluorescence distribution of substance P (SP) in WT and TLR $4^{-/-}$frozen sections (Figure 5D).

\section{TLR4 Modulates Inhibitory Neurotransmission}

Considering that nitrergic neurotransmission (Zizzo et al., 2004; Lomax et al., 2010), the primary inhibitory pathway in the gut, is affected by dysbiosis (Kabouridis and Pachnis, 2015), we tested whether the reduced excitatory contraction could be the result of an increase of the inhibitory component. Consistent with this prediction, a reduction of nitrergic neurons stained with NADPH diaphorase (NADPHd) or anti-nNOS was observed in TLR $4^{-/}$preparations (Figure 6). These changes were accompanied by a significant reduction of the total number of $\mathrm{HuC} / \mathrm{D}^{+}$neurons in $\mathrm{TLR} 4^{-/-}$myenteric plexus (Figures $6 \mathrm{C}-\mathrm{E}$ ). The reduction in $\mathrm{nNOS}^{+}$neurons was associated with a proportional increase of $\mathrm{VIP}^{+}$neurons in TLR4 ${ }^{-/-}$mice (Figure 6).

In NANC conditions EFS at $10 \mathrm{~Hz}$ caused a 1.48 -fold increase in relaxation in TLR $4^{-/-}$mice (Figure 7A). Pretreatment with $1400 \mathrm{~W}$, a selective inhibitor of iNOS, significantly reduced the NANC-mediated relaxation in TLR $4^{-/-}$mice (by $25.2 \pm 0.5 \%$, Figure 7A), whereas a slight but not significant relaxation $(13.8 \pm 0.9 \%$, Figure 7A) was recorded in WT. These findings support an involvement of iNOS in NO-mediated relaxation in the absence of TLR4. Furthermore, iNOS immunoreactivity increased by 5.7 -fold in TLR4 $4^{-/}$myenteric neurons and EGCs compared to WT (Figures 7B,C). Pretreatment with the pan-NOS inhibitor L-NAME almost completely blocked EFSevoked NANC relaxation in WT mice. Conversely, in TLR4 ${ }^{-/-}$ mice, this response was only partially abolished by L-NAME (Figure 7A) suggesting an influence of TLR4 in nitrergicmediated relaxation and possibly in other inhibitory pathways (e.g., purinergic or VIPergic), known to sustain intestinal contractility (Zizzo et al., 2004). Accordingly, we evaluated the role of adenosine and adenosine- $5^{\prime}$-triphosphate (ATP) in modulating relaxation in NANC conditions. Pretreatment with L-NAME and theophylline, a non-selective adenosine receptor antagonist, partially reduced the amplitudes of NANC-mediated relaxation in both genotypes whereas the addition of L-NAME and suramin, a non-selective ATP receptor antagonist, resulted in a significant reduction of the inhibitory response (by $75.3 \pm 1.5 \%$, Figure 7D) in TLR $4^{-/-}$mice, reaching a relaxation amplitude comparable to WT.

\section{TLR4 Absence Affects Purinergic Inhibitory Neurotransmission}

Considering that inhibitory neurotransmission in TLR $4^{-/-}$mice depends on both nitrergic and ATP-mediated relaxation, we evaluated the modulatory effect of ADP, the endogenous agonist of $\mathrm{P} 2 \mathrm{Y} 1$ receptors (P2Y1Rs). TLR4 ${ }^{-/-}$mice showed a 1.43 -fold increase in relaxation amplitude following addition of ADP in the organ bath with a significant shift to the left of the doseresponse curve to ADP compared to WT mice (Figure 8A). Since also enteric P2X7 receptors (P2X7Rs) respond to ATP 


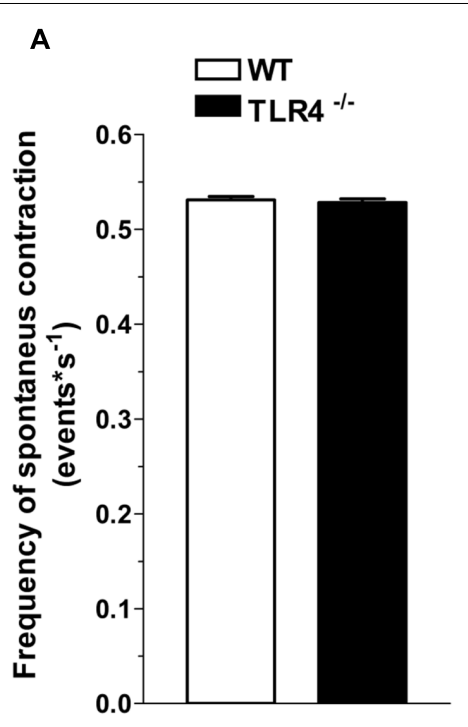

C

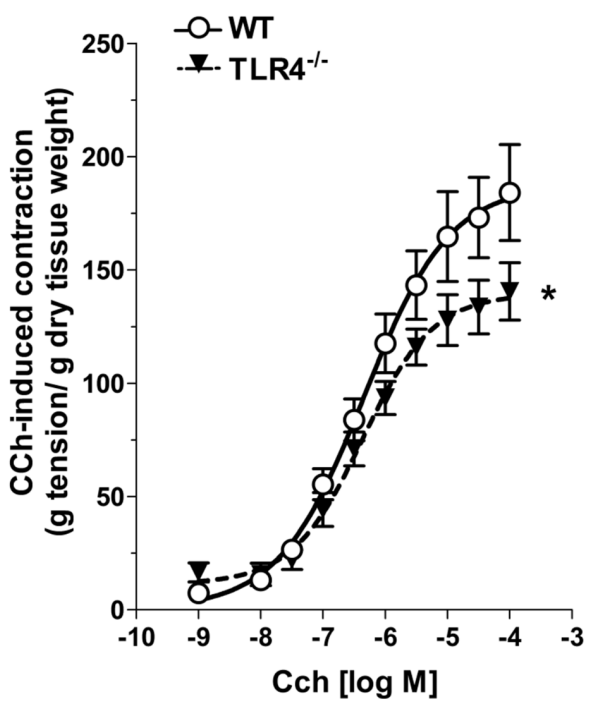

B

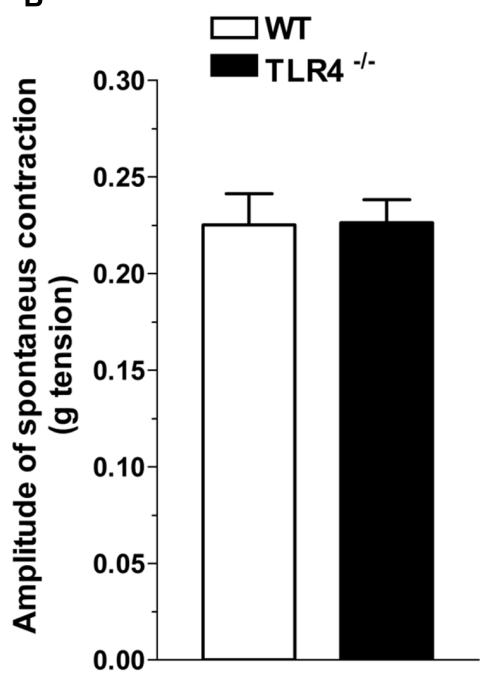

D

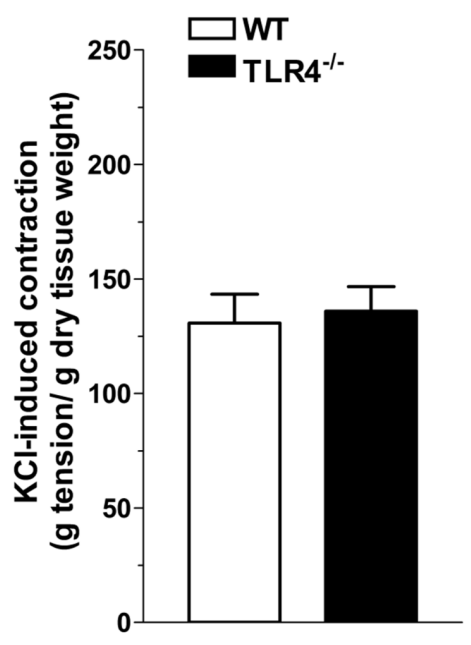

FIGURE 3 | TLR4 deficiency impairs contractile responses to carbachol but not to high $\mathrm{KCl}$. Frequency (A) and amplitude (B) of spontaneous contraction in WT and TLR4 ${ }^{-/}$- ileal preparations ( $N=15$ mice/group). Concentration-response curves to carbachol (CCh, $\mathbf{C}$ ) and $\mathrm{KCl}$-mediated excitatory response (D) in WT and TLR4 $^{-/}$- preparations ( $N=8$ mice/group). ${ }^{*} P<0.05$ vs. WT.

by mediating inhibitory neurotransmission and are involved in neuronal death during intestinal inflammation (Antonioli et al., 2014; Brown et al., 2015), we examined the influence of P2Y1Rs and P2X7Rs in NANC-mediated relaxation in the absence of TLR4. In ileal tissues from TLR $4^{-/}$mice, P2Y1Rs blockade with MRS2500 in presence of L-NAME markedly reduced the amplitudes of NANC-mediated relaxation (by $45.1 \pm 3 \%$ ) whereas the addition of A804598 (a selective P2X7Rs antagonist) determined a reduction of the inhibitory response (by $24.2 \pm 1.5 \%$, Figure 8B), suggesting an involvement of both receptors in modulating relaxation in NANC conditions in the absence of TLR4.
Immunohistochemical analysis revealed a 1.79 -fold increase of P2Y1Rs staining in myenteric ganglia, in both neurons and EGCs (Figure 9) and a 2.4-fold increase in P2X7Rs immunoreactivity in TLR $4^{-/-}$myenteric neurons, underlining the involvement of TLR4 in ensuring ENS homeostasis (Figure 10).

\section{DISCUSSION}

TLR4 plays a well-established regulatory role in the innate immune response to infection and in adaptive responses 

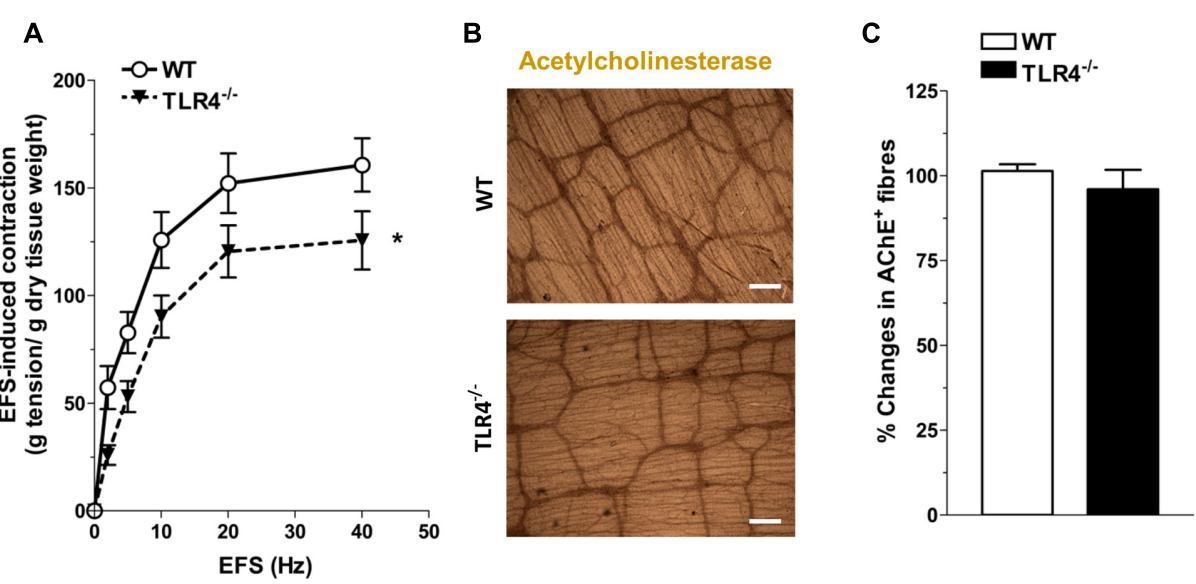

FIGURE 4 | TLR4 deficiency alters ileal excitatory contractility. (A) EFS-induced excitatory responses in WT and TLR4-/- preparations ( $N=8$ mice/group). Representative microphotographs showing the distribution (B) and \% changes (C) of $\mathrm{AChE}^{+}$fibers in WT and TLR4-/- preparations ( $N=5$ mice/group). Bars $=200 \mu \mathrm{m} .{ }^{*} P<0.05$ vs. WT.

consenting probiotic bacteria colonization. To date, several studies have evaluated the role of TLR4 in gut mucosa, mainly in colon, whereas only few have explored the impact of TLR4 in the ENS of small intestine (Anitha et al., 2012; Kabouridis and Pachnis, 2015).

Although polymorphisms in TLR4 gene affecting LPS signaling have been described in patients with chronic inflammatory bowel diseases (IBD), their pathophysiological relevance in neuroimmune cross talk is still unclear (Cario, 2010). In this regard, ENS appears to be directly involved in modulating the inflammatory response, since it express several TLRs, including TLR4, in enteric neurons and glial cells (Rumio et al., 2006; Sharkey and Savidge, 2014). In human longitudinal muscle-myenteric plexus (LMMP) and in rat ENS primary cultures, neural activation with EFS or ATP has been shown to inhibit LPS-induced TNF- $\alpha$ production through enteric neuronal P2X7R (Coquenlorge et al., 2014). However, it is becoming clear that TLR4 overstimulation by periodic intestinal infections, or its understimulation following excessive use of antibiotics have the potential to affect the balance between ENS-microbial-derived products early in life setting the basis for developing GFD in adulthood (Becattini et al., 2016).

Here, for the first time, we show the role of TLR4 on ENS structural and functional integrity and provide relevant insights into the underlying mechanisms. In particular, this study demonstrates that the absence of TLR4 results in: (i) altered distribution of the enteric glial markers GFAP and S100 $\beta$; (ii) decreased total number of $\mathrm{HuC} / \mathrm{D}^{+}$neurons; (iii) an altered nNOS $^{+}$-to-VIP ${ }^{+}$neuron ratio; (iv) impaired tonic cholinergic excitation; (v) enhanced inhibitory neurotransmission mediated by the coordinated action of both $\mathrm{NO}$ (from nNOS and iNOS) and ATP through the interaction with the purinergic P2X7Rs and P2Y1Rs.

Previous immunohistochemical analyses have shown the presence of TLR4 in gut neuromuscular layers, as well as in sensory dorsal root ganglia, suggesting that both intrinsic and extrinsic neuronal circuits possess the machinery to respond directly to microbiota-derived stimuli (Barajon et al., 2009). Indeed, our study showed that TLR4 deficiency does affect the distribution of $\mathrm{S} 100 \beta$ and GFAP, specific markers for EGCs (Gulbransen and Sharkey, 2012; Neunlist et al., 2014). Recently, the role of EGCs has started to emerge not only as a mechanical support for enteric neurons but as cellular integrative bridge of gut homeostasis involved in controlling neuroplasticity, mucosal barrier and inflammatory responses by releasing specific gliomediators (e.g., NO, ATP) (Gulbransen and Sharkey, 2012; Neunlist et al., 2014). Considering that the pathophysiological functions of GFAP and $S 100 \beta$ in the ENS are still under discussion and that $\mathrm{TLR}^{-/-}$mice showed no changes in mucosal permeability and inflammatory markers (as shown by us and others) (Peterson et al., 2010; Devaraj et al., 2011), the increases in these regulatory and structural proteins advocate for the presence of an underlying gliopathy in absence of TLR4 signaling. In support of this premise, increases in GFAP expression are associated with EGCs differentiation, inflammation, and injury (Ochoa-Cortes et al., 2016); S100 $\beta$ expression and release by ECGs at $\mu \mathrm{M}$ levels are linked to pathological conditions (Rühl, 2005); and EGCs gliosis, detected by increased GFAP levels and/or S100 $\beta$ immunoreactivity/release, has been reported in ulcerative colitis, microbial infection and neurodegenerative diseases (OchoaCortes et al., 2016).

Lipopolysaccharide hyporesponsiveness and delayed gastrointestinal transit were reported for $T l r 4^{L p s-d}$ mice on a $\mathrm{C} 3 \mathrm{H} / \mathrm{HeJ}$ background. However, our study was performed at earlier time points (30 min vs. $4 \mathrm{~h}$ ) following non-absorbable FITC-dextran administration to evaluate the involvement of the small intestine in the delayed transit. Although the reduced pellet frequency and water content may resemble the same colon dysmotility previously described in $T l r 4^{L p s-d}$ mice (Anitha et al., 2012), our mouse model has a spontaneous 

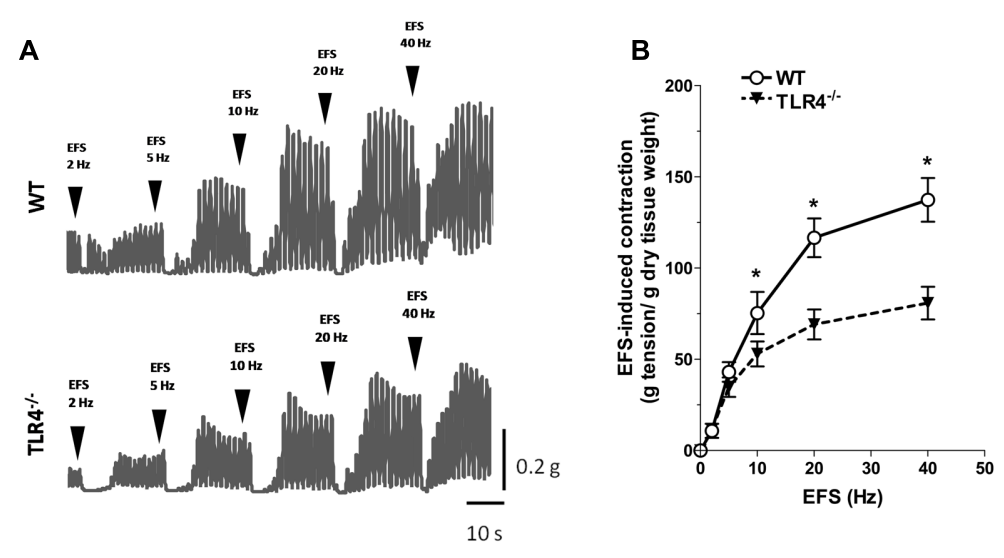

D
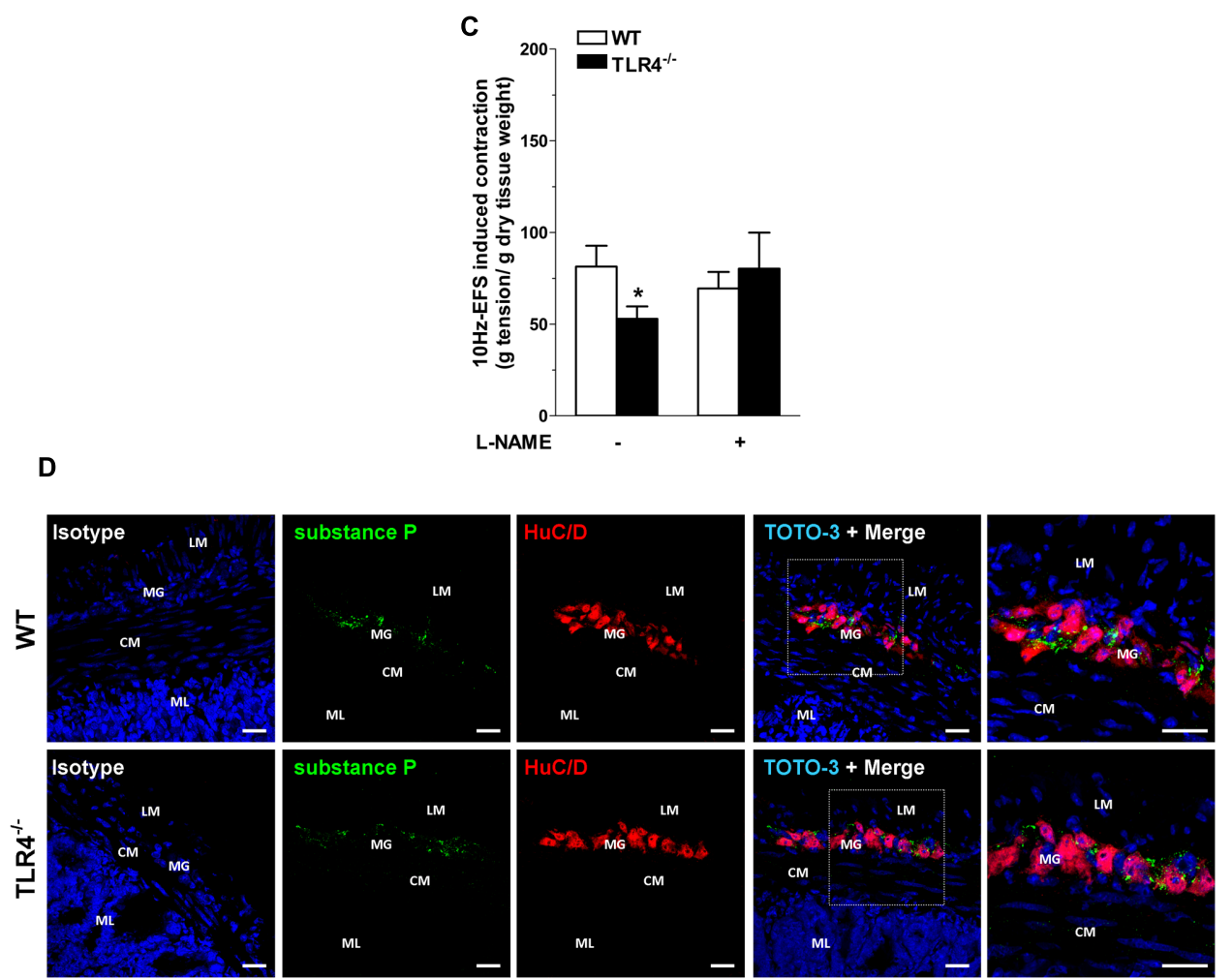

FIGURE 5 | Tachykininergic neurotransmission is not affected by TLR4 deficiency. (A) Representative traces of contractile responses to increasing EFS frequencies in WT and TLR4 ${ }^{-/-}$segments under NANC conditions. (B) NANC responses evoked by EFS. (C) Tachykininergic nerve-evoked contractions induced by $10 \mathrm{~Hz}-\mathrm{EFS}$, in NANC condition with or without L-NAME in WT and TLR4 ${ }^{-1-}$ preparations ( $N=8$ mice/group). (D) Representative confocal microphotographs of HuC/D (red) and substance P (green) distribution in WT and TLR4 ${ }^{-1-}$ cryosections. Cell nuclei were stained with TOTO-3 (blue; $N=5$ mice/group). Bars $=22 \mu \mathrm{m}$. LM, longitudinal muscle; CM, circular muscle; MG, myenteric ganglia; ML, mucosal layer. ${ }^{*} P<0.05$ vs. WT.

mutation that results in a complete loss-of-function of TLR4, whereas the $T l r 4^{L p s-d}$ mice have a point mutation causing an amino acid substitution. In our study, no differences in high potassium-induced contraction were revealed, suggesting that TLR4 deficiency does not influence smooth muscle function (Ratz et al., 2005). However, the downward shift of the concentration-response curve to both carbachol and EFS in $\mathrm{TLR}^{-/-}$preparations may be explained by the different contributing triggers to the onset of the reduced excitatory neuromuscular response, such as impaired cholinergic neurotransmission, higher level of inflammatory mediators or enhanced inhibitory non-adrenergic non-cholinergic transmission.

By expressing TLR4 and thus being sensitive to LPS, enteric neurons appear to be involved in the regulation of the innate tolerance response to microbial-derived products 
A

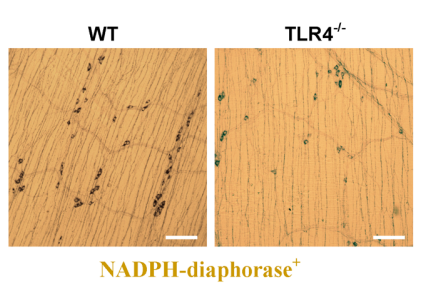

B

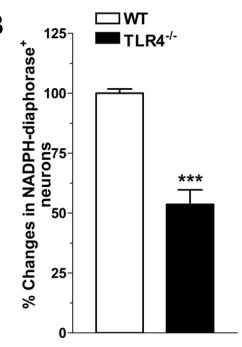

C

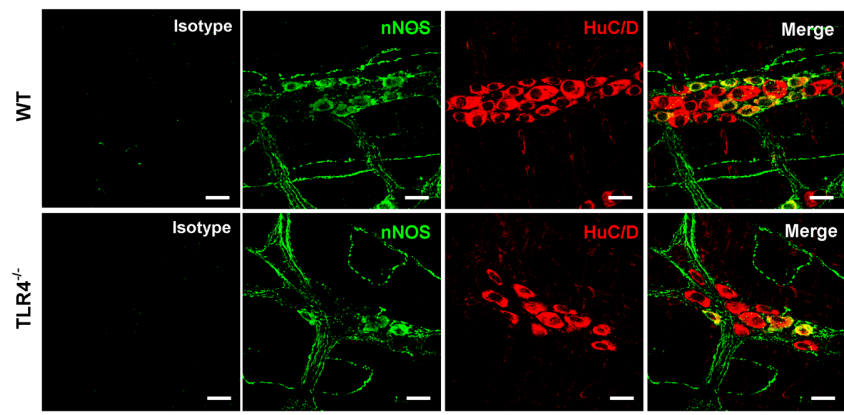

D
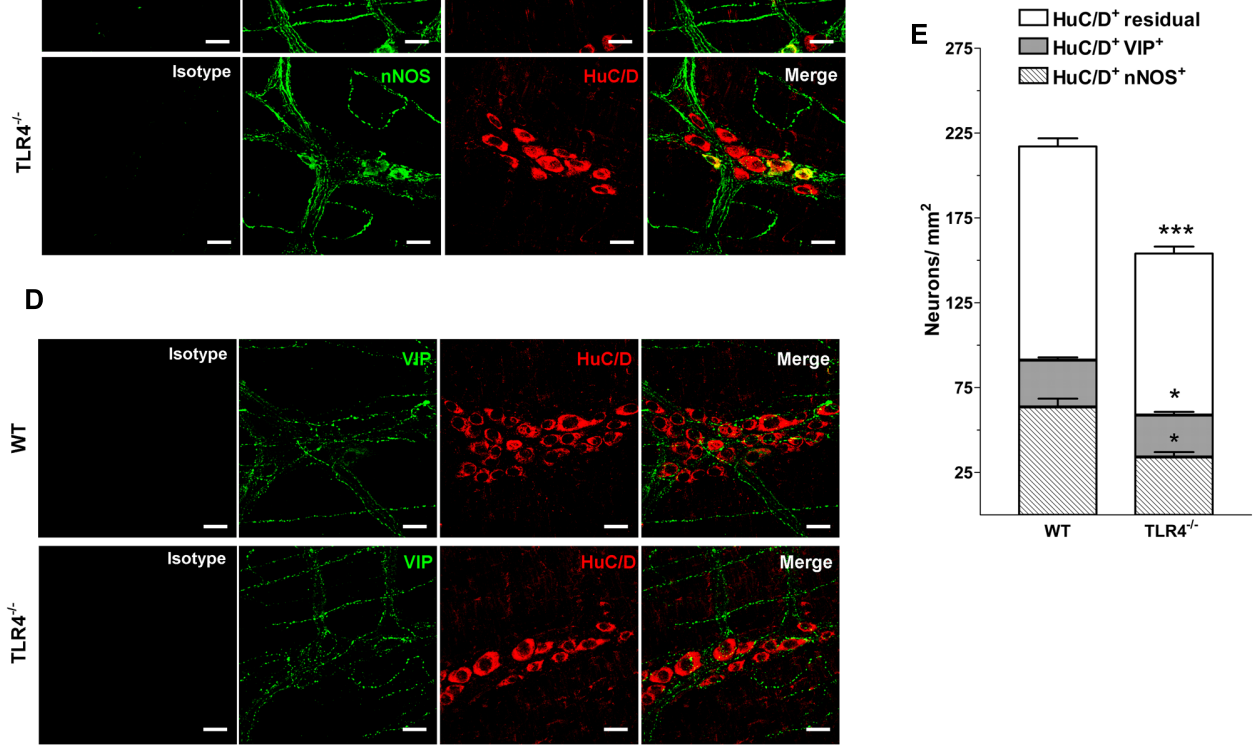

FIGURE 6 | TLR4 signaling modulates nitrergic and VIPergic neurotransmissions. Representative microphotographs showing the distribution (A) and density (B) of $\mathrm{NADPHd}^{+}$neurons in WT and TLR4 ${ }^{-/-}$LMMP preparations $(\mathrm{bars}=300 \mu \mathrm{m})$. Representative confocal microphotographs showing the distribution of nNOS $(\mathbf{C}$;

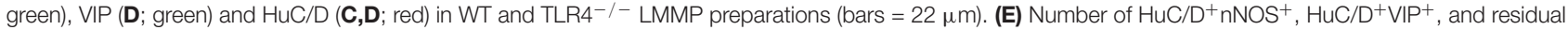
HuC/D ${ }^{+}$neurons in WT and TLR4 ${ }^{-/-}$LMMP preparations ( $N=8$ mice/group). ${ }^{*} P<0.05,{ }^{* * *} P<0.001$ vs. WT.

in the intestine, ensuring a balanced immune response with respect to luminal content. Both increased and decreased GI motility have been reported after LPS exposure, depending on the dose, timing between injection and assessments of GI motility, the region of the GI system that is investigated and the type of LPS (Bashashati et al., 2012). Low-grade inflammation in the gut can alter digestive motility, through changes in the functions of enteric nerves and/or smooth muscle cells, thus highlighting a pathophysiological relationship between bowel inflammation and abnormalities in enteric motor activity (Kabouridis and Pachnis, 2015). However, recent studies have detected no differences in the levels of several inflammatory markers measured in serum and in peritoneal macrophages in TLR4 $4^{-/}$animals compared to $\mathrm{C} 57 \mathrm{BL} / 6 \mathrm{~J}$ mice (Hritz et al., 2008; Zhang et al., 2008; Devaraj et al., 2011).
Alterations in tachykininergic pathways have been shown in GFD (Margolis and Gershon, 2009; Corsetti et al., 2015). Under NANC conditions, post-stimulus excitatory responses with L-NAME showed no differences between genotypes, consistent with a lack of TLR4 involvement in tachykininergic pathways also confirmed by immunohistochemistry of SP.

Since under certain conditions cholinergic nerve activity can be depressed (Anitha et al., 2006), the observed marked NANC-mediated relaxation indicates that impaired cholinergic neurotransmission results from an enhanced inhibitory control on cholinergic and noradrenergic transmission. The main inhibitory neurotransmitter NO can be generated by the three different enzymes, nNOS, eNOS, and iNOS. More than 90\% of the total NOS in the small intestine is nNOS, localized in inhibitory neurons. However, iNOS isoform is also constitutively present and accounts for less than $10 \%$ of the total enteric 


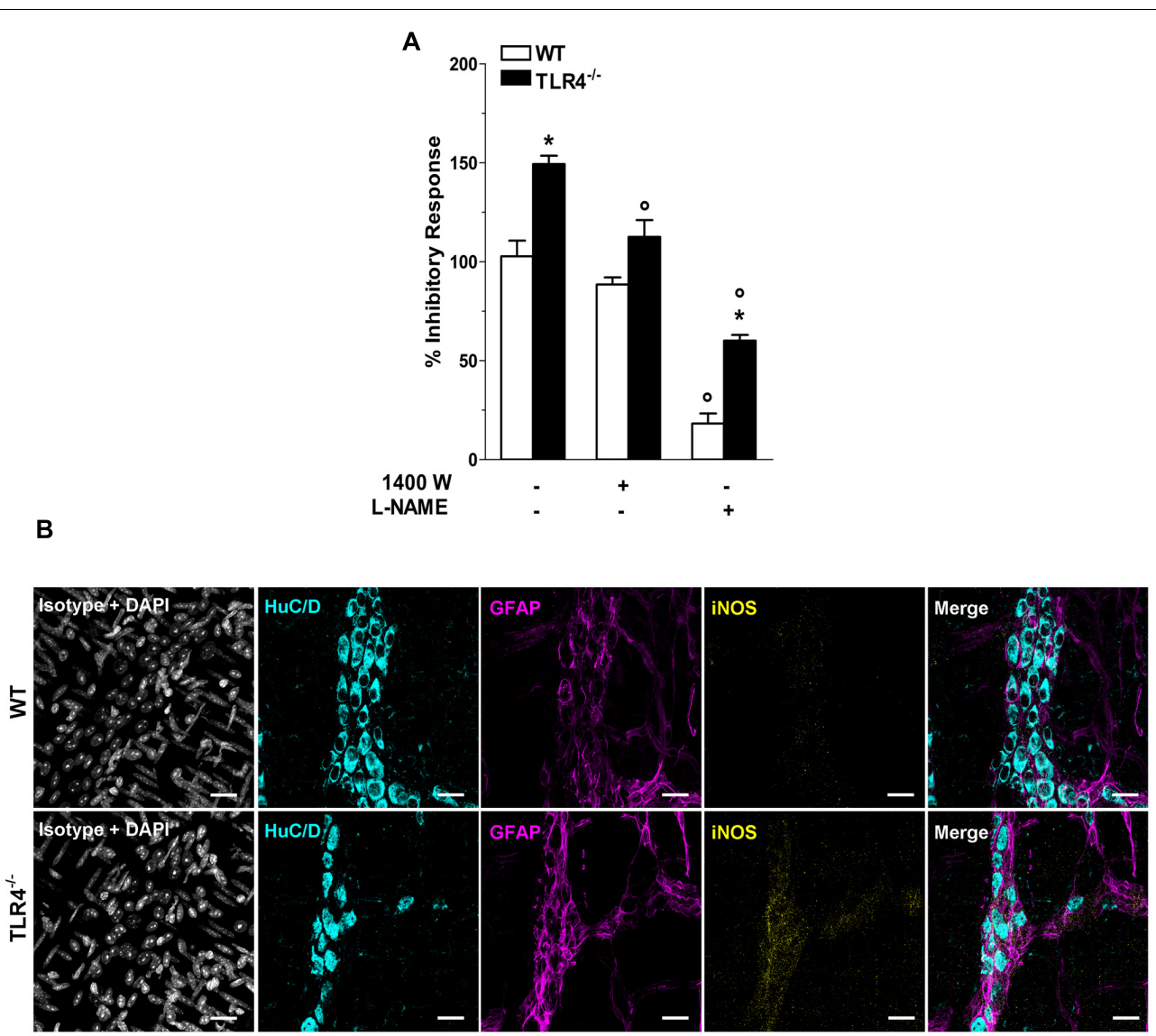

C

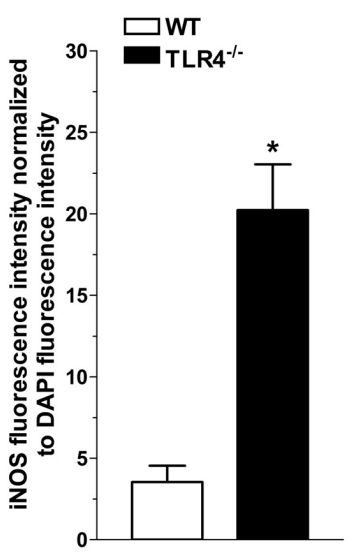

D

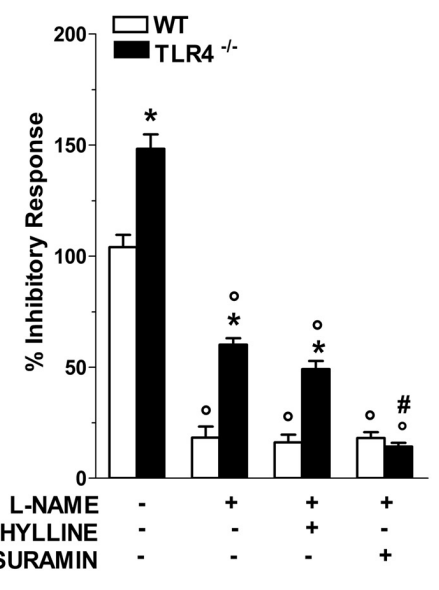

FIGURE 7 | TLR4 signaling modulates NO and P2 receptor-mediated relaxation. (A) $10 \mathrm{~Hz}$-EFS-evoked NANC relaxation responses with or without 1400 W or L-NAME in WT and TLR4 $4^{-/-}$preparations ( $N=8$ mice/group). (B) Representative confocal microphotographs showing HuC/D (cyan), GFAP (magenta) and iNOS (yellow) distribution (bars $=22 \mu \mathrm{m}$ ) and $\mathbf{( C )}$ analysis of changes in iNOS fluorescence intensity in WT and TLR4 ${ }^{-/-}$LMMP preparations ( $N=5$ mice/group). (D) $10 \mathrm{~Hz}$-EFS-evoked NANC relaxation responses with or without L-NAME+theophylline or L-NAME+suramin in WT and TLR4 ${ }^{-1}$ - preparations ( $N=8$ mice/group). ${ }^{*} P<0.05$ vs. WT; ${ }^{\circ} P<0.05$ vs. respective control without L-NAME; ${ }^{*} P<0.001$ vs. respective control with L-NAME.

NOS activity whereas eNOS isoform is barely detectable (Lu et al., 2006). In case of inflammation the induction of iNOS produces a large amount of NO with consequent intestinal dysmotility (Eskandari et al., 1999). NANC-mediated relaxation was increased in TLR4 ${ }^{-/-}$preparations and was mediated by NO produced by iNOS and nNOS, whereas in WT mice the inhibitory tone was mainly dependent on nNOS-derived NO. Moreover, $\mathrm{TLR}^{-/-}$myenteric ganglia contained a reduced number of 

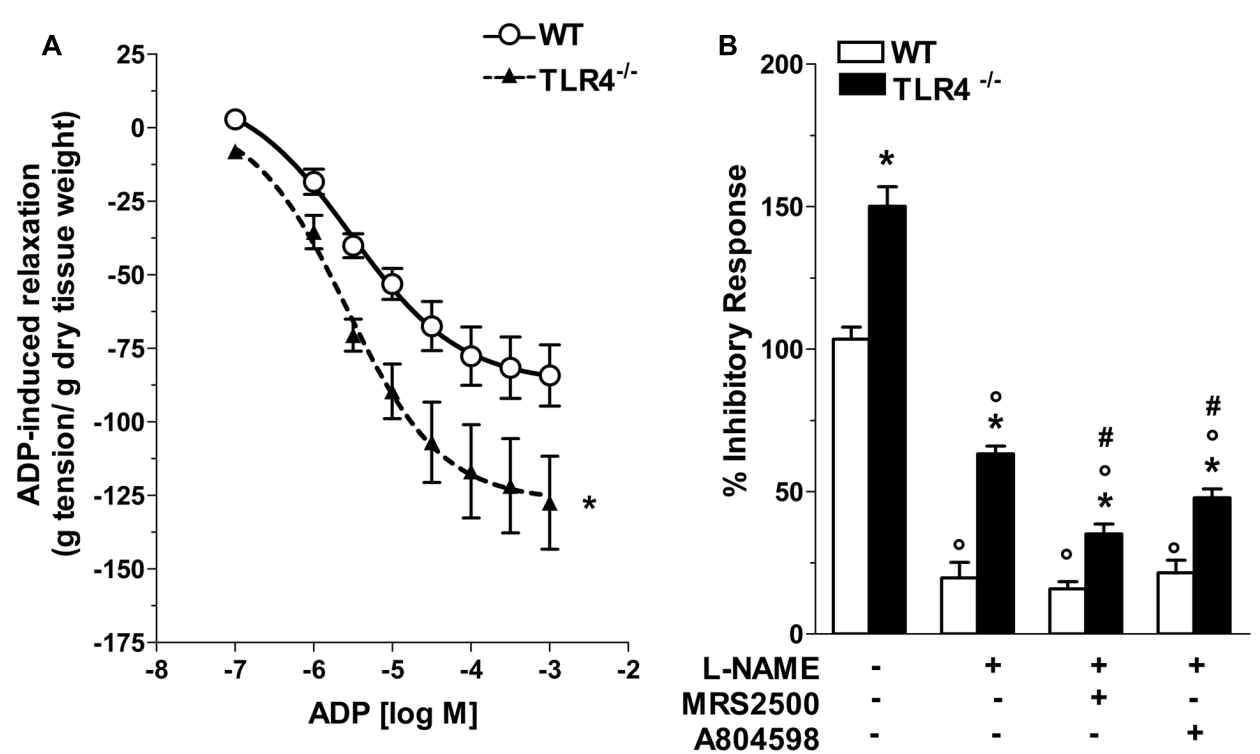

FIGURE 8 | Involvement of TLR4 signaling in purinergic neurotransmission. (A) Concentration-response curve to ADP in WT and TLR4 ${ }^{-/-}$preparations ( $N=8$ mice/group). (B) $10 \mathrm{~Hz}$-EFS-evoked NANC relaxation responses with or without L-NAME+MRS2500 (a P2Y1Rs antagonist) or L-NAME+A804598 (a P2X7Rs antagonist) in WT and TLR4 ${ }^{-/}$- preparations ( $N=8$ mice/group). ${ }^{*} P<0.05$ vs. WT; ${ }^{\circ} P<0.05$ vs. respective control without $L-N A M E ; ~ \# P<0.001$ vs. respective control with L-NAME.
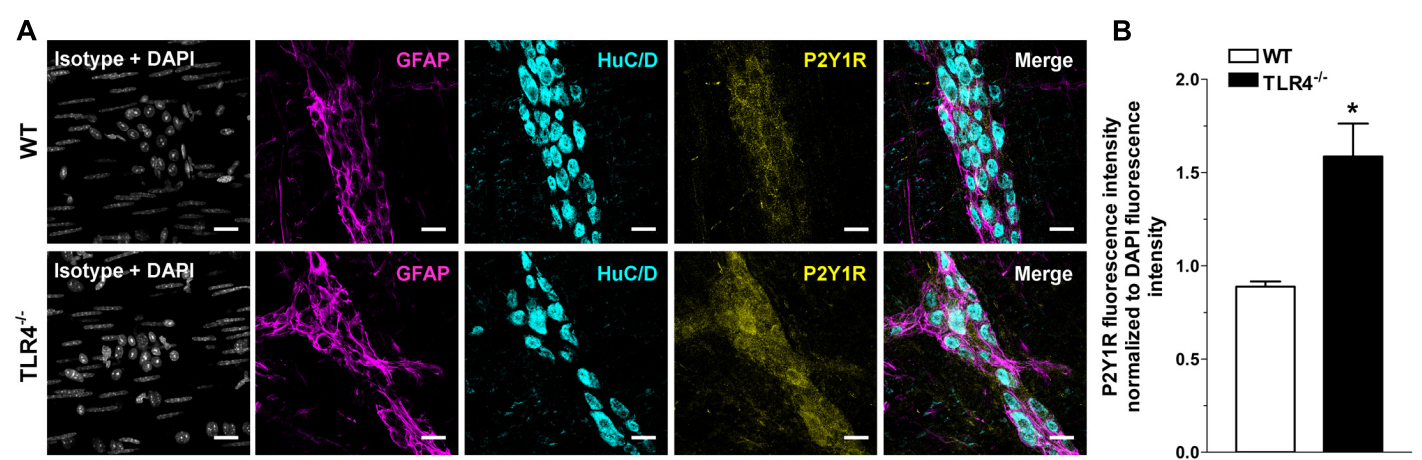

FIGURE 9 | TLR4 signaling influences P2Y1 receptor distribution. Representative confocal microphotographs showing (A) GFAP (magenta), P2Y1Rs (yellow) and $\mathrm{HuC/D}$ (cyan) distribution and (B) analysis of P2Y1Rs fluorescence intensities in WT and TLR4 ${ }^{-/-}$LMMP preparations (N $=5$ mice/group). Cell nuclei were stained with DAPI (gray). Bars $=22 \mu \mathrm{m} .{ }^{*} P<0.05$ vs. WT.

$\mathrm{HuC} / \mathrm{D}^{+}$neurons, associated to a proportional reduction of $\mathrm{nNOS}^{+}$neurons in agreement with our functional findings and as previously shown by Anitha et al. (2012) in whole mount preparations. However, we found that this reduction in nNOS $^{+}$neurons was accompanied with a proportional increase of $\mathrm{VIP}^{+}$neurons. VIP not only acts as a neurotransmitter but also plays a role in neuroprotection and functions as an anti-inflammatory agent (Ekblad and Bauer, 2004). These adaptive changes in the proportion of $\mathrm{VIP}^{+}$and $\mathrm{nNOS}^{+}$neurons with no modifications in SP-containing nerves appear to be phenotypic characteristics of ENS resembling those found in diabetic neuropathy (Voukali et al., 2011). At the functional level, the loss of TLR4 appears to influence the nitrergic pathway engaging other inhibitory transmitters responsible for the increased NANC relaxations. Our findings of gliosis and enhanced inhibitory tone, sensitive to both L-NAME and suramin (a non-selective P2 receptor antagonist), support the involvement of ATP in the ENS dysfunctions of TLR4 ${ }^{-/-}$ mice.

ATP is known to play important roles in gut function as well as in inflammation, since its $\mathrm{P} 2$ receptors are widely distributed in neurons, glia, smooth muscle, and immune cells (Burnstock, 2014). In mouse ileum, pharmacological studies (Giaroni, 2002; Gallego et al., 2014) have shown that in physiological conditions ATP modulates relaxation by acting via P2Y1Rs, the main receptor subtype mediating NANC inhibitory responses, partly by direct action on smooth muscle and partly by activating nNOS $^{+}$neurons that release ATP and NO. In the presence 


\section{A}

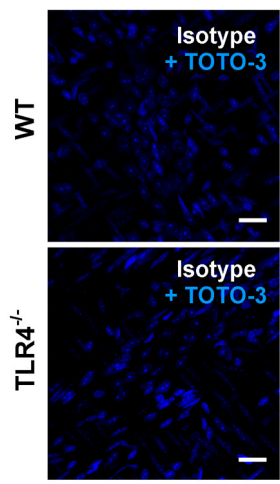

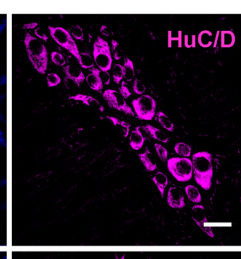

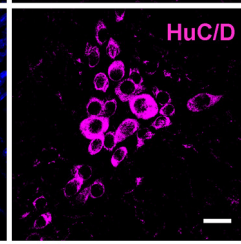

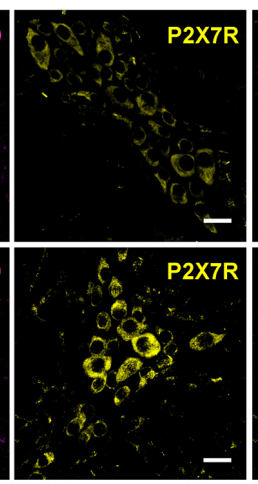

B

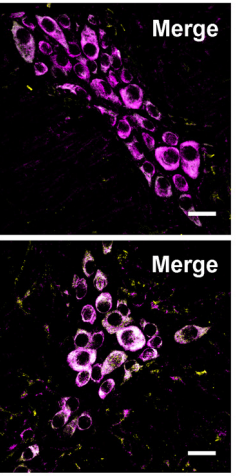

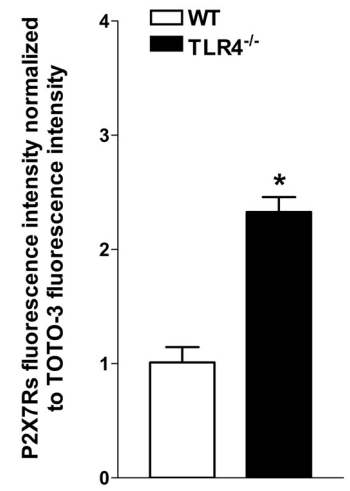

FIGURE 10| TLR4 signaling influences P2X7 receptor distribution. Representative confocal microphotographs showing (A) HuC/D (magenta) and P2X7Rs (yellow) distribution and (B) analysis of P2X7Rs fluorescence intensities in WT and TLR4 ${ }^{-/}$preparations ( $N=5$ mice/group). Cell nuclei were stained with TOTO-3 (blue). Bars $=22 \mu \mathrm{m} .{ }^{*} P<0.05$ vs. WT.

of inflammation, a overproduction of ATP activates the low affinity P2X7Rs, contributing significantly to activating inhibitory nitrergic neurons ( $\mathrm{Hu}$ et al., 2001; Antonioli et al., 2014). In this respect, it has been proposed that ATP released by enteric neurons can activate EGCs, which in turn through $\mathrm{Ca}^{2+}$ signals and release of gliotransmitters (e.g., ATP, glutamate, among others), communicate with other ECGs and neurons, influencing gut contractility (Ochoa-Cortes et al., 2016). Here, we found higher amplitude of relaxation to ADP (the P2Y1Rs endogenous ligand) and NANC-mediated responses sensitive to $\mathrm{P} 2 \mathrm{Y} 1$ and $\mathrm{P} 2 \mathrm{X} 7$ inhibition, together with an increase in immunoreactivities of P2Y1Rs, P2X7Rs and iNOS in TLR4 $4^{-/-}$ myenteric plexus. Our functional results support the notion that TLR4 deficiency influences ATP neurotransmission, activating myenteric P2X7Rs and P2Y1Rs and determining increased smooth muscle relaxation and iNOS-derived NO production potentially by enteric neurons and EGCs.

Recent studies so far have shown the involvement of TLR4 in the modulation of enteric neural stem/progenitor cells, and of neural survival (Anitha et al., 2012; Schuster et al., 2014), our work provides the first evidence of a cross-talk between TLR4 and nitrergic/purinergic pathways in enteric neuralglial communication (Rumio et al., 2006; Brown et al., 2015). Specifically, our study advocates for a new scenario in the ENS, where in the absence of TLR4, ATP pathways cooperate with nitrergic neurotransmission through P2Y1Rs and P2X7Rs as recently demonstrated by Brown et al. (2015).

\section{CONCLUSION}

Our study highlights for the first time a novel role for TLR4 in ileum, demonstrating that TLR4 fine-tunes ENS circuitry modulating the inhibitory component of neuromotor activity by $\mathrm{NO}$ and ATP co-transmission, essential for maintaining a proper bidirectional neural-glial communication. Our findings provides the basis for a better understanding of the mechanisms underlying gastrointestinal dysmotility in presence of an anomalous neuroimmune cross talk, thereby paving the way for the development of suitable pharmacological modulators of TLR4 signaling for the management of GFD.

\section{AUTHOR CONTRIBUTIONS}

Conceived and designed the experiments: MG, CG, GO, VC, IM, and EN. Performed the experiments: VC, IM, MoR, SC, and FG. Analyzed the data: VC, IM, GO, FG, EN, MaR, and IL. Contributed reagents/materials/analysis tools: $\mathrm{MG}, \mathrm{GO}, \mathrm{IL}$, and MaR. Wrote the manuscript: MG, VC, IM, CG, and EN. All the authors reviewed the manuscript.

\section{FUNDING}

This work was supported by grants from University of Padova (UNIPD-Assegno di Ricerca 2016 and UNIPD-ex 60\%-2015 funds) and from San Camillo Hospital, Treviso (Italy) to MG.

\section{ACKNOWLEDGMENTS}

We thank Francesca Patrese, DMV and Ludovico Scenna, DMV for veterinary assistance, Mauro Berto and Massimo Rizza for technical assistance in animal handling and experimental procedures, Vincenza Guzzardo, for histological experiments. The TLR4 ${ }^{-/-}$mice were kindly provided by Prof. Ignazio Castagliuolo (University of Padova, Italy) and Dr. Marco Scarpa (Veneto Institute of Oncology IOV - IRCCS, Padova, Italy). 


\section{REFERENCES}

Anitha, M., Gondha, C., Sutliff, R., Parsadanian, A., Mwangi, S., Sitaraman, S. V., et al. (2006). GDNF rescues hyperglycemia-induced diabetic enteric neuropathy through activation of the PI3K/Akt pathway. J. Clin. Invest. 116, 344-356. doi: 10.1172/JCI26295

Anitha, M., Vijay-Kumar, M., Sitaraman, S. V., Gewirtz, A. T., and Srinivasan, S. (2012). Gut microbial products regulate murine gastrointestinal motility via Toll-like receptor 4 signaling. Gastroenterology 143, 1006.e4-1016.e4. doi: 10. 1053/j.gastro.2012.06.034

Antonioli, L., Giron, M. C., Colucci, R., Pellegrini, C., Sacco, D., Caputi, V., et al. (2014). Involvement of the P2X7 purinergic receptor in colonic motor dysfunction associated with bowel inflammation in rats. PLOS ONE 9:e116253. doi: 10.1371/journal.pone.0116253

Aravalli, R. N., Peterson, P. K., and Lokensgard, J. R. (2007). Toll-like receptors in defense and damage of the central nervous system. J. Neuroimmune Pharmacol. 2, 297-312. doi: 10.1007/s11481-007-9071-5

Arqués, O., Chicote, I., Tenbaum, S., Puig, I., and Palmer, H. G. (2014). Quantitative procedure to analyze nuclear $\beta$-catenin using immunofluorescence tissue staining. Protoc. Exchange doi: 10.1038/protex. 2012.008

Aubé, A.-C., Cabarrocas, J., Bauer, J., Philippe, D., Aubert, P., Doulay, F., et al. (2006). Changes in enteric neurone phenotype and intestinal functions in a transgenic mouse model of enteric glia disruption. Gut 55, 630-637. doi: 10 . 1136/gut.2005.067595

Barajon, I., Serrao, G., Arnaboldi, F., Opizzi, E., Ripamonti, G., Balsari, A., et al. (2009). Toll-like receptors 3, 4, and 7 are expressed in the enteric nervous system and dorsal root ganglia. J. Histochem. Cytochem. 57, 1013-1023. doi: 10.1369/jhc.2009.953539

Barbara, G., Feinle-Bisset, C., Ghoshal, U. C., Quigley, E. M., Santos, J., Vanner, S., et al. (2016). The intestinal microenvironment and functional gastrointestinal disorders. Gastroenterology 150, doi: 10.1053/j.gastro.2016.02.028 [Epub head of print].

Bashashati, M., Storr, M. A., Nikas, S. P., Wood, J. T., Godlewski, G., Liu, J., et al. (2012). Inhibiting fatty acid amide hydrolase normalizes endotoxin-induced enhanced gastrointestinal motility in mice. Br. J. Pharmacol. 165, 1556-1571. doi: 10.1111/j.1476-5381.2011.01644.x

Becattini, S., Taur, Y., and Pamer, E. G. (2016). Antibiotic-induced changes in the intestinal microbiota and disease. Trends Mol. Med. 22, 458-478. doi: 10.1016/ j.molmed.2016.04.003

Bischoff, S. C., Barbara, G., Buurman, W., Ockhuizen, T., Schulzke, J.-D., Serino, M., et al. (2014). Intestinal permeability - a new target for disease prevention and therapy. BMC Gastroenterol. 14:189. doi: 10.1186/s12876-0140189-7

Brown, I. A. M., McClain, J. L., Watson, R. E., Patel, B. A., and Gulbransen, B. D. (2015). Enteric glia mediate neuron death in colitis through purinergic pathways that require connexin-43 and nitric oxide. Cell. Mol. Gastroenterol. Hepatol. 57, 742-768. doi: 10.1002/dev.21214

Brun, P., Giron, M. C., Qesari, M., Porzionato, A., Caputi, V., Zoppellaro, C., et al. (2013). Toll-like receptor 2 regulates intestinal inflammation by controlling integrity of the enteric nervous system. Gastroenterology 145, 1323-1333. doi: 10.1053/j.gastro.2013.08.047

Brun, P., Gobbo, S., Caputi, V., Spagnol, L., Schirato, G., Pasqualin, M., et al. (2015). Toll like receptor-2 regulates production of glial-derived neurotrophic factors in murine intestinal smooth muscle cells. Mol. Cell. Neurosci. 68, 24-35. doi: 10.1016/j.mcn.2015.03.018

Burnstock, G. (2014). Purinergic signalling in the gastrointestinal tract and related organs in health and disease. Purinergic Signal. 10, 3-50. doi: 10.1007/s11302013-9397-9

Cario, E. (2010). Toll-like receptors in inflammatory bowel diseases: a decade later. Inflamm. Bowel Dis. 16, 1583-1597. doi: 10.1002/ibd.21282

Coquenlorge, S., Duchalais, E., Chevalier, J., Cossais, F., Rolli-Derkinderen, M., and Neunlist, M. (2014). Modulation of lipopolysaccharide-induced neuronal response by activation of the enteric nervous system. J. Neuroinflammation 11:202. doi: 10.1186/s12974-014-0202-7

Corsetti, M., Akyuz, F., and Tack, J. (2015). Targeting tachykinin receptors for the treatment of functional gastrointestinal disorders with a focus on irritable bowel syndrome. Neurogastroenterol. Motil. 27, 1354-1370. doi: 10.1111/nmo.12616
Dall'Olmo, L., Fassan, M., Dassie, E., Scarpa, M., Realdon, S., Cavallin, F., et al. (2014). Role of proton pump inhibitor on esophageal carcinogenesis and pancreatic acinar cell metaplasia development: an experimental in vivo study. PLoS ONE 9:e112862. doi: 10.1371/journal.pone.0112862

De Mello, S. T., De Miranda Neto, M. H., Zanoni, J. N., and Furlan, M. M. D. P. (2009). Effects of insulin treatment on $\mathrm{HuC} / \mathrm{HuD}, \mathrm{NADH}$ diaphorase, and nNOS-positive myoenteric neurons of the duodenum of adult rats with acute diabetes. Dig. Dis. Sci. 54, 731-737. doi: 10.1007/s10620-008-0430-8

Devaraj, S., Tobias, P., and Jialal, I. (2011). Knockout of toll-like receptor-4 attenuates the pro-inflammatory state of diabetes. Cytokine 55, 441-445. doi: 10.1016/j.cyto.2011.03.023

Ekblad, E., and Bauer, A. J. (2004). Role of vasoactive intestinal peptide and inflammatory mediators in enteric neuronal plasticity. Neurogastroenterol. Motil. 16, 123-128. doi: 10.1111/j.1743-3150.2004.00487.x

Eskandari, M. K., Kalff, J. C., Billiar, T. R., Lee, K. K. W., and Bauer, A. J. (1999). LPS-induced muscularis macrophage nitric oxide suppresses rat jejunal circular muscle activity. Am. J. Physiol. Gastrointest. Liver Physiol. 277, G478-G486.

Gallego, D., Malagelada, C., Accarino, A., De Giorgio, R., Malagelada, J. R., Azpiroz, F., et al. (2014). Nitrergic and purinergic mechanisms evoke inhibitory neuromuscular transmission in the human small intestine. Neurogastroenterol. Motil. 26, 419-429. doi: 10.1111/nmo.12293

Giaroni, C. (2002). P2 receptors in the murine gastrointestinal tract. Neuropharmacology 43, 1313-1323. doi: 10.1016/S0028-3908(02)00294-0

Giron, M. C., Bin, A., Brun, P., Etteri, S., Bolego, C., Florio, C., et al. (2008). Cyclic AMP in rat ileum: evidence for the presence of an extracellular cyclic AMPadenosine pathway. Gastroenterology 134, 1116-1126. doi: 10.1053/j.gastro. 2008.01.030

Gulbransen, B. D., and Sharkey, K. A. (2012). Novel functional roles for enteric glia in the gastrointestinal tract. Nat. Rev. Gastroenterol. Hepatol. 9, 625-632. doi: 10.1038/nrgastro.2012.138

Hritz, I., Mandrekar, P., Velayudham, A., Catalano, D., Dolganiuc, A., Kodys, K., et al. (2008). The critical role of toll-like receptor (TLR) 4 in alcoholic liver disease is independent of the common TLR adapter MyD88. Hepatology 48, 1224-1231. doi: 10.1002/hep.22470

Hu, H. Z., Gao, N., Lin, Z., Gao, C., Liu, S., Ren, J., et al. (2001). P2X(7) receptors in the enteric nervous system of guinea-pig small intestine. J. Comp. Neurol. 440, 299-310. doi: 10.1002/cne.1387

Kabouridis, P. S., and Pachnis, V. (2015). Emerging roles of gut microbiota and the immune system in the development of the enteric nervous system. J. Clin. Invest. 125, 956-964. doi: 10.1172/JCI76308

Kamada, N., Chen, G. Y., Inohara, N., and Núñez, G. (2013). Control of pathogens and pathobionts by the gut microbiota. Nat. Immunol. 14, 685-690. doi: $10.1038 /$ ni.2608

Lecci, A. (2002). Pharmacology of transmission to gastrointestinal muscle. Curr. Opin. Pharmacol. 2, 630-641. doi: 10.1016/S1471-4892(02)00225-4

Lee, K. N., and Lee, O. Y. (2014). Intestinal microbiota in pathophysiology and management of irritable bowel syndrome. World J. Gastroenterol. 20, 88868897. doi: $10.3748 /$ wjg.v20.i27.8886

Lomax, A. E., Sharkey, K. A., and Furness, J. B. (2010). The participation of the sympathetic innervation of the gastrointestinal tract in disease states. Neurogastroenterol. Motil. 22, 7-18. doi: 10.1111/j.1365-2982.2009.01381.x

Lu, H., Zhu, B., and Xue, X.-D. (2006). Role of neuronal nitric oxide synthase and inducible nitric oxide synthase in intestinal injury in neonatal rats. World J. Gastroenterol. 12, 4364-4368. doi: 10.3748/wjg.v12.i27.4364

Margolis, K. G., and Gershon, M. D. (2009). Neuropeptides and inflammatory bowel disease. Curr. Opin. Gastroenterol. 25, 503-511. doi: 10.1097/MOG. 0b013e328331b69e

McGrath, J. C., and Lilley, E. (2015). Implementing guidelines on reporting research using animals (ARRIVE etc.): new requirements for publication in BJP. Br. J. Pharmacol. 172, 3189-3193. doi: 10.1111/bph.12955

McQuade, R. M., Carbone, S. E., Stojanovska, V., Rahman, A., Gwynne, R. M., Robinson, A. M., et al. (2016). Role of oxidative stress in oxaliplatin-induced enteric neuropathy and colonic dysmotility in mice. Br. J. Pharmacol. 173, 3502-3521. doi: 10.1111/bph.13646

Morrison, H. W., Filosa, J. A., Roger, V., Go, A., Lloyd-Jones, D., Benjamin, E., et al. (2013). A quantitative spatiotemporal analysis of microglia morphology during ischemic stroke and reperfusion. J. Neuroinflammation 10:4. doi: 10.1186/17422094-10-4 
Neunlist, M., Rolli-Derkinderen, M., Latorre, R., Van Landeghem, L., Coron, E., Derkinderen, P., et al. (2014). Enteric glial cells: recent developments and future directions. Gastroenterology 147, 1230-1237. doi: 10.1053/j.gastro.2014.09.040

Ochoa-Cortes, F., Turco, F., Linan-Rico, A., Soghomonyan, S., Whitaker, E., Wehner, S., et al. (2016). Enteric glial cells. Inflamm. Bowel Dis. 22, 433-449. doi: 10.1097/MIB.0000000000000667

Okun, E., Griffioen, K. J., and Mattson, M. P. (2011). Toll-like receptor signaling in neural plasticity and disease. Trends Neurosci. 34, 269-281. doi: 10.1016/j.tins. 2011.02.005

Orso, G., Martinuzzi, A., Rossetto, M. G., Sartori, E., Feany, M., and Daga, A. (2005). Disease-related phenotypes in a Drosophila model of hereditary spastic paraplegia are ameliorated by treatment with vinblastine. J. Clin. Invest. 115, 3026-3034. doi: 10.1172/JCI24694

Peterson, C. Y., Costantini, T. W., Loomis, W. H., Putnam, J. G., Wolf, P., Bansal, V., et al. (2010). Toll-like receptor-4 mediates intestinal barrier breakdown after thermal injury. Surg. Infect. (Larchmt). 11, 137-144. doi: 10. 1089/sur.2009.053

Rakoff-Nahoum, S., Paglino, J., Eslami-Varzaneh, F., Edberg, S., and Medzhitov, R. (2004). Recognition of commensal microflora by toll-like receptors is required for intestinal homeostasis. Cell 118, 229-241. doi: 10.1016/j.cell.2004.07.002

Ratz, P. H., Berg, K. M., Urban, N. H., and Miner, A. S. (2005). Regulation of smooth muscle calcium sensitivity: $\mathrm{KCl}$ as a calcium-sensitizing stimulus. Am. J. Physiol. Cell Physiol. 288, C769-C783. doi: 10.1152/ajpcell.00529.2004

Riehl, T. E., Santhanam, S., Foster, L., Ciorba, M., and Stenson, W. F. (2015). CD44 and TLR4 mediate hyaluronic acid regulation of Lgr5+ stem cell proliferation, crypt fission, and intestinal growth in postnatal and adult mice. Am. J. Physiol. Gastrointest. Liver Physiol. 309, G874-G887. doi: 10.1152/ajpgi.00123.2015

Rühl, A. (2005). Glial cells in the gut. Neurogastroenterol. Motil. 17, 777-790. doi: 10.1111/j.1365-2982.2005.00687.x

Rumio, C., Besusso, D., Arnaboldi, F., Palazzo, M., Selleri, S., Gariboldi, S., et al. (2006). Activation of smooth muscle and myenteric plexus cells of jejunum via Toll-like receptor 4. J. Cell. Physiol. 208, 47-54. doi: 10.1002/jcp.20632

Schuster, A., Klotz, M., Schwab, T., Di Liddo, R., Bertalot, T., Schrenk, S., et al. (2014). Maintenance of the enteric stem cell niche by bacterial lipopolysaccharides? Evidence and perspectives. J. Cell. Mol. Med. 18, 14291443. doi: $10.1111 / \mathrm{jcmm} .12292$

Sharkey, K. A., and Savidge, T. C. (2014). Role of enteric neurotransmission in host defense and protection of the gastrointestinal tract. Auton Neurosci. 181, 94-106. doi: 10.1016/j.autneu.2013.12.006

Voukali, E., Shotton, H. R., and Lincoln, J. (2011). Selective responses of myenteric neurons to oxidative stress and diabetic stimuli. Neurogastroenterol. Motil. 23, 964-e411. doi: 10.1111/j.1365-2982.2011.01778.x

Zhang, B., Ramesh, G., Uematsu, S., Akira, S., and Reeves, W. B. (2008). TLR4 signaling mediates inflammation and tissue injury in nephrotoxicity. J. Am. Soc. Nephrol. 19, 923-932. doi: 10.1681/ASN.2007090982

Zizzo, M. G., Mule, F., and Serio, R. (2003). Duodenal contractile activity in dystrophic (mdx) mice: reduction of nitric oxide influence. Neurogastroenterol. Motil. 15, 559-565. doi: 10.1046/j.1365-2982.2003. 00438.x

Zizzo, M. G., Mulè, F., and Serio, R. (2004). Interplay between PACAP and NO in mouse ileum. Neuropharmacology 46, 449-455. doi: 10.1016/j.neuropharm. 2003.09.011

Zoppellaro, C., Bin, A., Brun, P., Banzato, S., Macchi, V., Castagliuolo, I., et al. (2013). Adenosine-mediated enteric neuromuscular function is affected during herpes simplex virus type 1 infection of rat enteric nervous system. PLoS ONE 8:e72648. doi: 10.1371/journal.pone.0072648

Conflict of Interest Statement: The authors declare that the research was conducted in the absence of any commercial or financial relationships that could be construed as a potential conflict of interest.

Copyright (C) 2017 Caputi, Marsilio, Cerantola, Roozfarakh, Lante, Galuppini, Rugge, Napoli, Giulivi, Orso and Giron. This is an open-access article distributed under the terms of the Creative Commons Attribution License (CC BY). The use, distribution or reproduction in other forums is permitted, provided the original author(s) or licensor are credited and that the original publication in this journal is cited, in accordance with accepted academic practice. No use, distribution or reproduction is permitted which does not comply with these terms. 